Fernando Fogliano *

\title{
Arte interativa e 0 inconsciente maquínico
}

Fernando Fogliano Pós-doutorado pelo programa de Pós-Graduação em Artes da UNESP, doutor e mestre em Comunicação e Semiótica pela PUC - SP, Co-cordenador do Grupo Ciência Arte e Tecnologia cAt-UNESP. Integrante do Grupo Internacional de Pesquisas em Convergências entre Arte, Ciência e Tecnologia da UNESP, GIIP. Professor colaborador do Programa de Pós-Graduação em Artes da UNESP. Pesquisa narrativas visuais e interativas; implicações estéticas, cognitivas e tecnológicas da relação entre imagem e interatividade; estratégias de mediação e interação na produção artística no âmbito da neuroestética e das teorias da linguagem. Integrante do grupo SCIArts e o grupo cAt-UNESP.

<fernandofogliano@gmail.com> ORCID: 0000-0002-3088-6063
Resumo A história da tecnologia é também aquela em que a cultura permitiu a externalização das potencialidades humanas através de instrumentos e máquinas. $\mathrm{O}$ surgimento dos computadores parece dar continuidade àquele processo da expansão para o ambiente, ou extrassomatização, de nossos cérebros e capacidades cognitivas. Interessa-nos neste estudo considerar que sistemas automatizados construídos com base no uso da Inteligência Artificial, principalmente aqueles utilizados em obras de arte interativa, possam ser entendidos como extrassomatização de um particular aspecto dos processos cognitivos: o automatismo inconsciente. As linguagens computacionais estão no bojo desse processo, entendidas aqui também como parte de um fenômeno de complexificação da cultura. Pretende-se refletir sobre o papel criativo ensejado por processos automáticos inteligentes, desempenhados pelos sistemas interativos, entendidos como a possibilidade tecnológica de concretizar, nas máquinas, ações inconscientes complexas, uma espécie de gestualidade maquínica, fruto de um inconsciente maquínico.

Palavras chave Arte interativa, Software, Inteligência artificial, Robôs de conversação.

\section{Interactive Art and the Machinic Unconscious}

Abstract The history of technology is also the one in which culture allowed the externalization of human potentialities through instruments and machines. The emergence of computers seems to give continuity to that process of the expansion into the environment, or extra somatization of our brains and cognitive abilities. It is interesting in this study to consider that automated systems, based on the use of Artificial Intelligence, especially those used in interactive art works, can be understood as extra somatization of a special aspect of the cognitive processes: the unconscious automatism. Computational languages live at the heart of this process, understood here as part of a phenomenon of cultural complexity. The aim is to reflect on the creative role played by intelligent automatic processes, performed by interactive systems, understood as the technological possibility of realizing, in machines, complex unconscious actions, a kind of machinic gesturality, from a a machinic unconscious.

Keywords Artificial Intelligence, Chat Bots, Interactive Art, Software. 


\section{Introdução}

O presente artigo busca trazer uma reflexão sobre os robôs de conversação e os Autômatos Poéticos de Fabio Oliveira Nunes. Pretende-se fazer algumas considerações que permitam contribuir para a reflexão sobre a produção contemporânea no terreno da arte mediada por computadores, principalmente aquelas que utilizam algoritmos e técnicas de Inteligência Artificial (IA). A discussão realizada por Nunes em seu livro "Mentira de artista" é tão fascinante que nos obriga a parar e olhar para trás. Somos impelidos a buscar as origens do processo histórico que permitiu a emergência na arte, de robôs de conversação, da inteligência artificial, para tentar montar um cenário que possa dar algum sentido à complexa configuração cultural contemporânea.

\section{Arte: pigmentos e superfícies}

A humanidade tem testemunhado, ao longo dos aproximadamente últimos 40 mil anos, o uso dos mais diversos recursos tecnológicos serem utilizados para a inscrição das narrativas que compõem a cultura. Nesse longo período podemos perceber que, subjacente a essa inscrição, existe a necessidade de encontrar uma superfície e um pigmento para dar-lhes concretude, sem a qual não há alternativa para sequer sabermos de sua existência. Nossos sentidos, através de nossos sensores perceptivos, são instigados a percebê-las e alimentar um complexo processo cognitivo que permita a emergência, na a mente consciente, de um sentido ou significado. Inscrever narrativas apresenta invariavelmente um problema tecnológico: compatibilizar pigmentos e superfícies. A solução encontrada deve atender a requisitos de estabilidade e durabilidade a fim de configurar a memória cultural, extrasomática, estável e duradoura, capaz de permitir que nos comuniquemos com nossos semelhantes através do espaço e do tempo. Memorizadas em diferentes superfícies e pigmentos, histórias vão permitir que eventos, vividos ou imaginados, ideias, descrições, etc., possam ser contados, rememorados. Essa ação comunicativa vai permitir a tecitura das tramas da cultura serem construídas para dar suporte às realidades que fundam nossas relações intersubjetivas e com a natureza, em todo seu espectro de ecossistemas. Inscrever narrativas sobre suportes tem sua origem num evento dramático na história na humanidade. Alguns autores, como Mithen (2002), o denominaram Big Bang da mente. A Arte é considerada por ele como um dos propulsores da cultura. A Arte demanda por tecnologias para memorização de narrativas fora do corpo, extrasomáticas. Inscritas, num primeiro momento nas paredes e, posteriormente, num processo cuja história pode ser contada até a contemporaneidade, numa miríade de suportes. 


\section{Arte e tecnologia}

Como vimos, a tecnologia é o elemento da cultura que subjaz a capacidade que compatibilizar pigmento e superfície. Podemos considerar como esse processo de compatibilização que vem ocorrendo ao longo dos séculos determina os rumos e a velocidade em que a cultura evolui e se diversifica. Podemos relacionar os grandes impactos socioculturais experimentados ao longo da história da cultura à evolução dos suportes, os meios de comunicação e, mais recentemente, à mídia digital. Kittler $(2005$, p. 79$)$ ordena cronologicamente a evolução dos meios de comunicação, destacando o fato de que a invenção da escrita introduz o uso de "variáveis físicas", como instrumentos e superfícies. São estas variáveis que passam a determinar a estrutura espacial e temporal da comunicação. A imprensa, um estágio importante da evolução da escrita, "potencializava a capacidade de processamento de dados dos livros" (idem, p.85). Certamente porque livros produzidos em série garantiram paralelismo no consumo das informações neles contidas. Ao descrever as "mídias técnicas", o autor destaca uma mudança na estrutura física das mensagens que passam a fazer uso de "processos físicos que são mais rápidos do que a percepção humana e que só são suscetíveis de formulação no código da matemática" (idem, p.89), aumentando a velocidade na disseminação da informação. 0 surgimento desses processos marca a desmaterialização da informação na medida em que passam a utilizar luz e som na codificação das mensagens. Posteriormente, já no século XIX, avanços na Física tornaram possível o uso de impulsos elétricos e a codificação da informação em ondas eletromagnéticas. $O$ rádio e a televisão viabilizaram a transmissão de informação à velocidade da luz e um enorme paralelismo no processo de comunicação, permitindo a grandes massas receber simultaneamente toda sorte de mensagens. Esse processo de massificação e paralelismo tem sua escala enormemente ampliada com o surgimento das tecnologias digitais, com o emprego dos computadores e das redes digitais de comunicação como a Internet. Todo o processo evolutivo caracterizado pela quase desmaterialização da informação e o paralelismo dos processos de comunicação atende à necessidade de manter-se a estrutura e organização da sociedade humana na busca pelo estabelecimento de coerência interna na representação e comportamento nos seus múltiplos e variados grupos (FOGLIANO, 2010).

A arte, como aspecto fundamental da cultura humana, tem participação decisiva nesse desenvolvimento, demandando por inovações definindo requisitos como velocidade, paralelismo e reprodutibilidade. As paredes, telas e papéis, novos meios de inscrição narrativa como as telas de vídeo, sistemas de projeção, sistemas de impressão, possibilitam a expansão de nosso acervo de memórias. Novas tecnologias a expandir recursos narrativos, dando-lhes novos significados, estabelecendo novos vínculos com a natureza e com a sociedade humana. As tecnologias digitais deram suporte a um extenso conjunto de práticas e manifestações relacionados ao binômio Arte e Mídia. Software art, Internet Art, Arte Generativa, Glitch Art, Videogame Art, estão entre inúmeras outras modalidades de manifestação artística que têm, nos suportes digitais, seu instrumento de concretização. 


\section{Tecnologia e processo criativo}

Contemporaneamente, as tecnologias estão imbricadas num processo de complexidade consideravelmente maior daquele do início do século XX. Observa-se hoje o surgimento, no bojo das tecnologias digitais, de grande diversidade de suportes e de novas ferramentas para produção e disseminação das narrativas, sejam elas produzidas no campo da literatura, do cinema, das artes visuais, da música ou das contemporâneas formas narrativas híbridas onde se pode experimentar obras onde as formas clássicas narrativas aparecem "contaminadas" por outras como, por exemplo, os textos literários hipertextuais, a fotografia e vídeo interativos, etc. As narrativas encontram, no círculo de abstração narrativa e mediação tecnológica, o motor que alavanca linguagem e tecnologia levando a humanidade a expandir seus limites de atuação, de inovação e de experienciação. Nesse contexto, autores e leitores ou espectadores, agora também interagentes, envolvem-se num processo criativo a partir do qual emergem novas linguagens, abrindo caminho para o alargamento das possibilidades expressivas da arte e suas narrativas (FOGLIANO, 2013). A introdução de Inteligência Artificial se apresenta como um caminho natural de experimentação para as Artes, assim como o foram as demais tecnologias da informática. Contudo aqui, pode-se perceber um elemento de novidade. A Inteligência Artificial não incorpora um novo suporte, mas um novo elemento narrativo, embora processos criativos apoiados por computador não constituam novidade no campo da arte. Laurentiz (2003) está entre os artistas e críticos contemporâneos para os quais o uso de algoritmos computacionais utilizados nos processos criativos na produção artística borrou a separação existente entre os sistemas vivos e as máquinas, permitindo atribuir-lhes propriedades antes pertencentes somente aqueles sistemas vivos, para ela

\footnotetext{
...programado no computador que apresenta muitas propriedades dos sistemas vivos, incluindo os mecanismos de reprodução, herança, variação e seleção. Em trabalhos de arte que utilizam estes processos, a estética contribui para o desenvolvimento do sistema como um catalisador de interesses e preferências que, num processo externo a ele, é capaz de guiar o curso de sua evolução. Este é o método adotado por muitos artistas e que permite ao usuário a elaboração estética do ambiente, imagens, composições musicais etc. sem, contudo, ter total controle sobre eles, pois o sistema é auto gerativo (LAURENTIZ, 2003, p.47).
}

A novidade que os robôs de conversação representam está no fato de que, a depender do contexto, eles podem se passar por um interlocutor humano. $O$ próprio Alan Turing, cientista da computação, matemático, lógico, que esteve muito ligado ao desenvolvimento da ciência da computação teórica considerou essa possibilidade. Entre suas importantes con- 
tribuições para a ciência está a formalização dos conceitos de algoritmo e computação. Turing, percebendo o potencial de inteligência imbricada na execução de algoritmos computacionais chegou a conceber um teste no qual, sob condições apropriadas, seria difícil saber numa conversa entre dois interlocutores, qual seria o computador. Não faz mais sentido, nos dias de hoje, considerar plausível o Teste de Turing. Para Floridi (2016) Inteligência Artificial verdadeira não é logicamente impossível, mas é totalmente implausível. Não temos ideia de como podemos começar a engendrá-la, até porque temos pouca compreensão de como funcionam nossos próprios cérebros e uma definição definitiva para inteligência. Nesse contexto há de se definir um aspecto fundamental da inteligência humana, a consciência. Embora a consciência seja um mistério científico, Damásio fez considerações a seu respeito muito oportunas para a presente discussão:

\footnotetext{
Sem consciência - isto é, uma mente dotada de subjetividade - você não teria como saber que você existe, muito menos saberia quem você é, e o que você pensa. Não tivesse surgido a subjetividade, mesmo que muito modestamente a princípio, em criaturas muito mais simples do que nós, a memória e o raciocínio provavelmente não teriam se expandido da maneira prodigiosa que fizeram, e a estrada evolucionária para a linguagem e a elaborada versão da consciência que agora possuímos, não teria sido pavimentada. Criatividade não teria florescido. Não haveria música, nem pintura, nem literatura. O amor nunca teria sido amor, apenas sexo. A amizade teria sido mera conveniência cooperativa. A dor nunca teria se tornado sofrimento - nem uma coisa ruim, chegou a pensar nisso, mas uma vantagem ambígua, dado que o prazer não teria se tornado felicidade também. Caso a subjetividade não fizesse sua radical aparição, não haveria conhecimento e ninguém para tomar conhecimento, e consequentemente, não teria havido história do que criaturas fizeram através das idades, e nem nenhuma cultura (Damásio, 2012, s/n, location 142).
}

A consciência, portanto, é uma característica que surge nos seres vivos, nos humanos, em especial. Ao lado da biologia, alavanca processos subjacentes à evolução da espécie, a cultura. Constitui um aspecto de nosso processo cognitivo que nos permite saber que as experiências que vivemos são nossas, nos permite ser protagonistas de nossos atos, constitui nosso self. A consciência permitiu o surgimento do Homo Sapiens Sapiens, uma subespécie da família hominídea, do gênero Homo, o homem que sabe que sabe.

Com o avanço das tecnologias da informação e informática as empresas estão utilizando em seus sistemas operacionais, de atendimento on line, e outros serviços com assistentes inteligentes. Robôs de conversação de última geração utilizam tecnologias de reconhecimento e síntese de voz aliados a algoritmos estatísticos. Desse tipo de processamento, aquele que causa mais impacto sobre o público não especializado, é o denominado re- 
des neurais. Tal algoritmo foi inventado por Walter Pitts, neurocientista computacional e Warren McCulloch, neurofisiologista. Com sua compreensão sofisticada do cérebro humano, observaram a semelhança com a abordagem estatística da análise em camadas. Semelhante aos neurônios no cérebro humano, as redes neurais são formadas por modelos matemáticos de neurônios interconectados que interagem entre si. $O$ algoritmo foi inventado há mais de 40 anos. Naquela época as redes possuíam apenas dois níveis de profundidade. Hoje, com o avanço na tecnologia de processamento de informação, as redes neurais chegam a possuir até cem camadas de neurônios, embora o algoritmo propriamente tenha mudado pouco (Theobald, 2017; p. 70). Deep learning, uma nova denominação para redes neurais, é um algoritmo que permite a identificação de padrões e as probabilidades de suas ocorrências. Aplicados a imensos conjuntos de dados, como aqueles presentes nas bases de informação presentes na Internet - Big Data ${ }^{1}$, têm se mostrado uma ferramenta estratégica para a tomada de decisão. Tais sistemas poderão, num futuro muito próximo, ser utilizados na interação com uma série de atividades operacionais, prestação de serviços e outras atividades antes realizadas apenas por seres humanos. Essa tecnologia trará consequências transformadoras como aquelas provocadas pela revolução industrial no final do século XIX.

Apesar de estarem no cerne da revolução da informação, os robôs de conversação não fazem nada além de previsões estatísticas, ou detecção de padrões. Algoritmos no interior de computadores ainda não foram capazes de fazer neles emergir consciência, ainda que o conceito de vida tivesse de ser revisto frente a inteligência inequívoca que tais algoritmos atribuem aos computadores. Estas máquinas, habitadas por algoritmos oriundos das técnicas de inteligência artificial, são inconscientes. A expansão da memória nos livros e computadores, pode ser comparada a extrassomatização de processos cognitivos inconscientes nas máquinas, que poderíamos denominar de inconsciente maquínico. Processos inconscientes são corriqueiros na natureza, como afirma Bargh:

\footnotetext{
Processos inconscientes são inteligentes e adaptáveis em todo o mundo vivo, como Dawkins $(1976)^{2}$ sustentou, e as evidências da pesquisa psicológica que surgiu desde o tempo de sua escrita confirmou que este princípio se estende aos seres humanos também. Na natureza, a "mente inconsciente" é a regra, não a exceção (Bargh and Morsella, 2008).
}

A inteligência é o aspecto que determina no vivo a perspectiva da sobrevivência. Isso implica que o indivíduo deve ser capaz de desenvolver uma série de ações coordenadas no meio ambiente como: encontrar alimento, abrigo, evitar tornar-se presa de outros, usar o cartão de crédito, etc. Inteligência implica a necessidade de desenvolver e empregar, com base em estímulos sensórios, um conjunto de regras táticas baseadas nas regula- 
ridades, ou padrões, e propriedades ambientais, de forma a antecipar o resultado de um possível movimento. Podemos reconhecer nessa descrição a própria definição de conhecimento que fica armazenado em nossa memória interna e também é armazenado nas inscrições culturais (FOGLIANO, 2008).

Padrões ambientais e sua detecção, codificação e inserção no corpo da cultura são, portanto, a chave para o êxito na busca pela permanência da sociedade humana. Esta é precisamente a posição que ocupam as tecnologias de Inteligência Artificial e seus agentes inteligentes, robôs de conversação, sistemas de controle de veículos autônomos - motoristas robóticos, etc. São inteligentes, mas não conscientes. Não podem discernir, julgar conscientemente suas decisões. Podem ser máquinas muito úteis, mas são destituídas de julgamento. Leem mas não entendem, detectam padrões, mas não lhe atribuem significado. Podem substituir humanos em tarefas repetitivas e monótonas apenas.

Hansen (2006; p. 77-82) busca diferenciar semanticamente os conceitos de informação e significado. Considerado o aspecto concernente a Teoria da Informação de Shannon, a informação contida numa dada mensagem representa uma escolha num intervalo de mensagens possíveis, deve ser definida probabilisticamente: não diz respeito ao que uma mensagem em particular diz tanto quanto o que não diz. Por esta razão, a informação deve ser separada do significado, que pode, na melhor das hipóteses, formar um nível suplementar subordinado. $O$ significado emerge da ação da estrutura interna do receptor que executa a crucial função de converter estímulos de entrada em "símbolos internos". Neste processo de conversão, a atividade interna do receptor gera estruturas simbólicas que servem para contextualizar estímulos. É o trabalho da consciência que cria as conexões de sentido, ainda que essas conexões não se deem de forma automática. Hansen utiliza o termo "improvisada" para referir-se a estas conexões construtoras de sentido na consciência do receptor ${ }^{3}$. É precisamente neste ponto que surge o papel criativo da consciência. Para Gazzaniga (2011), consciência é uma propriedade emergente. No contexto das teorias da complexidade, emergência é o fenômeno que abre possibilidade para a inovação. Concluindo, robôs de conversação e tecnologias da inteligência artificial são inteligências inconscientes, não criam, não têm ética; estas são atribuições daqueles que as empregam, humanos dotados de consciência. Máquinas são plataformas para humanos expandirem suas potencialidades.

\section{Arte interativa e o inconsciente maquínico}

Simondon (2007, p.33) nos dá o fundamento necessário para as afirmações feitas no final do segmento anterior. Para ele a máquina dotada de alta tecnicidade é a máquina aberta a interação e, um conjunto de máquinas abertas supõe o homem como organizador permanente, como intérprete vivo de máquinas em rede. Longe de ser o vigilante de uma sociedade de escravos, o homem é o organizador permanente de uma sociedade de objetos 
técnicos que dele têm necessidade como os músicos têm do maestro. Ao considerar a abertura dos objetos técnicos, Simondon os coloca no universo da emergência, da criatividade, da imprevisibilidade e da inovação inesgotável. Como sistemas abertos, objetos técnicos são inerentemente criativos, e em sua relação com o homem e outros objetos técnicos vão dar azo à emergência a novas redes de relações com outros objetos técnicos. Essa característica aproxima-se do conceito simondoneano de individuação, que "os aproximaria da noção de indivíduo presente na biologia, em que cada indivíduo constitui um conjunto de dispositivos articulados que formam um corpo em separado" (CAMPOS e CHAGAS) deslocando o ponto de vista da reflexão sobre a tecnologia para o da adaptação darwiniana (FOGLIANO,2013).

Mimo Stein é um exemplo emblemático do que se afirmou anteriormente. Fábio Nunes criou esse personagem baseado num algoritmo de IA denominado Eliza. Criado para imitar um psicanalista em uma conversa com seu paciente, Eliza instiga o analisado com questões compiladas a partir das sua próprias respostas. O personagem Mimo Stein é um artista paulista que trabalha com web art. Em 2012, cria o seu trabalho mais significativo, uma teleperformance intitulada "O artista está telepresente (2013)". Nesse trabalho o jovem artista passa a ter contato interpessoal não presencial a qualquer momento (NUNES, 2016, p.177). Nunes comenta sobre os diálogos realizados por seu personagem algorítmico:

\footnotetext{
Mimo Stein tentará problematizar algumas dessas opiniões como um provocador que não se fixa em posições claras para as questões que dispara (...) Mimo também instiga a discussão sobre questões de alteridade, afinal, ainda que não se apresente como tal, é uma persona baseada em um robô de conversação (idem, p. 193).
}

O robô de conversação Mimo Stein surpreende de forma análoga a ilusão realista produzida pela fotografia no século XIX. O personagem algorítmico de Fabio Nunes nos faz acreditar que suas respostas são oriundas de uma mente consciente. Ao expor sua mágica em seu instigante livro, Nunes nos mostra o papel criativo das máquinas a operar como plataforma para a inventividade do artista numa reflexão necessária sobre o papel da tecnologia na cultura. Essa perspectiva se aproxima daquela dada por Peres e Fogliano (2017, p.158):

\footnotetext{
Mesmo se constituindo em um sistema fechado, onde elementos distintos são agrupados e se auto-correlacionam de maneira orgânica, o objeto técnico possui uma abertura ao novo, que Simondon nomeia de função superabundante. A superabundância indica a existência de um espaço aberto à criação, sendo um lugar propício a uma interação fértil com o ser humano. Por este motivo, podemos fazer uma associação direta com a construção de narrativas, pois é neste espaço sensível que o ser humano
} 
irá articular seu pensamento e suas memórias para o estabelecimento de novas relações. Enquanto a máquina trabalha com uma memória específica, armazenando informações e proporcionando uma fidelidade de dados, o sujeito que interage com ela utilizará sua própria memória, de outra natureza, para estabelecer novas conexões e atribuir significados em função de um contexto ou necessidade. Temos, assim, uma relação de reciprocidade entre ambos, objetos e palavras, que é oposta à ideia de dominação.

Mimo Stein aponta para a tecnologia como suporte para as narrativas. Organizadas por máquinas para serem lidas e recriadas por mentes conscientes. Um jogo de mentiras sinceras, criadas de modo a revelar a alma humana e sua infindável criatividade. Ao mesmo tempo, o artista nos revela um fenômeno assustador que pode e, certamente provocará, imensas consequências não somente no mundo das artes, como no mundo do trabalho, social e político.

1 Big data é um conjunto de dados tão volumoso e complexo que o software tradicional de processamento de dados é inadequado para lidar com eles. Os desafios do Big Data incluem a captura de dados, armazenamento de dados, análise de dados, pesquisa, compartilhamento, transferência, visualização, consulta, atualização, privacidade de informações e fonte de dados. Existem cinco conceitos associados ao big data: volume, variedade, velocidade e, recentemente adicionados, veracidade e valor. (Wikipedia - https://en.wikipedia.org/wiki/Big_data)

2 Bargh refere-se ao livro 0 Gene Egoísta.

3 Utilizou-se o termo "receptor" em referência à Teoria da Informação presente no texto de Hansen. Poderíamos utilizar o termo interagente considerado o contexto artístico interativo proposto neste texto.

\section{Referências}

BARGH, J. A.; MORSELLA, E. The Unconscious Mind. Perspectives on Psychological Science, v. 3, n. 1, p. 73-79, 2008.

CAMPOS, Jorge Lucio de \& CHAGAS, Filipe. Os conceitos de Gilbert Simondon como fundamentos para o design. In: Bibliotenca on-line de Ciências da Comunicação. 2008. Disponível em: <http://pt.scribd.com/doc/55929022/ Campos-Jorge-ChagasFilipe-Conceitos-de-GilbertSimondon>. Acesso realizado em:03/03/2017. DAMASIO, A. Self comes to mind: constructing the conscious brain. New York: Pantheon Books. Edição do Kindle, 2010.

DONALD, Merlin. Origins of the Modern Mind: Three stages in the evolution of FLORIDI, Luciano. Should we be afraid of AI?. Aeon, published in 9th May 2016. Available 
from: https://aeon.co/essays/true-ai-is-both-logically-possible-and-utterly-implausible. FOGLIANO, Fernando. O Atrator Poético : a Arte no estudo do Design da Interação The Atrator Poético : Art in the study of Design of Interaction. Rev. da Associação Estudos em Design - Puc-Rio, v. 15, p. 1-17, 2008. \#9.Art - 9o Encontro Internacional de Arte e Tecnologia. Cultura Imaterial: Linguagem, Arte e Tecnologia. 2010. . Cultura e Tecnologia: A Automação nos Processos Criativos das Narrativas. Revista da Anpoll, V1, n35 (2013). ISSN 1982-7830.

GAZZANIGA, Michael S. Who's in Charge?: Free Will and the Science of the Brain . HarperCollins. Edição do Kindle, 2011.

HANSEN, Mark B. N. New Philosophy for new Media. Cambridge: MIT Press, 2006. KITTLER, Friedrich. A história dos meios de comunicação in O Chip e o Caleidoscópio: Reflexões sobre as novas mídias. Lucia Leão (org.). São Paulo: Editora Senac de São Paulo, 2005, p. 73-100. LAURENTIZ, Silvia. Processos computacionais evolutivos na arte. ARS (São Paulo)[online]. 2003, vol.1, n.2 [cited 2018-03-31], pp.45-55. Available from: <http://www.scielo.br/scielo. php?script=sci_arttext\&pid=S1678-53202003000200004\&lng=en\&nrm=iso>. ISSN 1678-5320. http://dx.doi.org/10.1590/S1678-53202003000200004

MITHEN, Steven. A pré-história da mente: uma busca das origens da arte, da religião e da ciência. São Paulo: Editora UNESP, 2002.

NUNES, Fabio Oliveira. Mentira de Artista. São Paulo: Comogonias Elétricas, 2016. PERES, Carolina e Fogliano, Fernando. 0 pensamento simondoneano e a imagem contemporânea. Revista do Programa de Pós-Graduação em Comunicação e Cultura da Escola de Comunicação de Universidade Fedreral do Rio de Janeiro. Gilbr Simondon. v.20, N.1, 2017 THEOBALD, Oliver. Machine Learning for Absolute Beginners: A Plain English Introduction (First Edition) (pp. 71-72). Scatterplot Press. Edição do Kindle, 2017. 